\title{
The Impact of Spinal Cord Injury on South African Youth
}

\begin{abstract}
Approximately 500 South Africans, mainly young people, sustain a spinal cord injury every year leading to severe lifetime physical disabilities. With advances in medicine and assistive technology, these young people are able to reach adulthood. The physical, social and emotional adjustments, which determine the eventual successful outcome following injury, vary considerably from person to person. Some make satisfactory adjustments whereas others remain chronically distressed. This study aimed to determine the impact of SCI on youth in community settings after discharge from rehabilitation. A qualitative approach, that

Njoki E, MSc. Physiotherapy'; Frantz J, PhD Physiotherapy; Mpofu R, PhD².

1 Department of Physiotherapy,

University of the Western Cape.

2 Associate Professor, Department of

Physiotherapy, University of the Western Cape.

${ }^{3}$ Dean, Professor, Department of Physiotherapy, University of the Western Cape. utilised face-to-face interviews and focus group methods of data collection, was used. Data were drawn from ten participants selected at Conradie Spinal Rehabilitation Unit, using purposive sampling. Audiotape recorded interviews were transcribed verbatim. Strong themes that ran through the data were identified. The results of the study revealed that spinal cord injury impacts on more than just the physical capabilities of an individual. Participants identified issues such as social identity, intrapersonal and interpersonal factors, social support and employment opportunities as having a major impact on their lives once back in the community. It is recommended that rehabilitation professionals include issues such as identity and psychosocial adjustment into their health promotion interventions.
\end{abstract}

KEY WORDS: YOUTH, SPINAL CORD INJURY, IMPACT, QUALITATIVE.

\section{INTRODUCTION}

Spinal cord injury, usually caused by trauma, often results in severe lifetime physical disabilities and occurs most frequently in young people (Nesathurai, 2000). It is a devastating problem that may substantially impact on many facets of an individual's life, including social roles, personal goals and future life expectations (Conroy and Mc Kenna, 1999). The physical, social and emotional adjustments, which determine the eventual successful outcome following injury, vary considerably from person to person with some making satisfactory adjustments whereas others remain chronically distressed (Chase et al,

\section{CORRESPONDENCE TO:}

\section{Prof JM Frantz}

Department of Physiotherapy

University of the Western Cape

Private Bag x17

Bellville 7530

Tel: 2721 959-2542

Fax: 2721 959-1217

E-mail: jfrantz@uwc.ac.za
2000). Factors such as architectural barriers, discriminatory society attitudes and unemployment have been identified as some of the distressing physical and social adjustment problems that SCI individuals encounter once back in the community (Levins et al, 2004).

Physiotherapists are among the key health care providers that treat SCI individuals and spend a long time with them. Physiotherapists therefore commonly establish a good relationship with SCI individuals that last long after discharge from the hospital or rehabilitation setting. According to Frieg and Hendry (2001), in order to be in line with the primary health care concept of service delivery, it is the role of the physiotherapist to deliver CBR services to persons with disabilities. The aim of this study was to determine the impact of SCI on the youth in community settings once discharged from rehabilitation.

\section{METHOD}

Ethical clearance was obtained from the deputy director of the Rehabilitation Centre at Conradie Hospital now known as the Western Cape Rehabilitation Centre. Informed written consent was obtained from the participants participating in the study.

\section{Subjects}

Purposive sampling was used to select 10 participants from the hospital's medical records. All participants recruited had been patients at the Conradie Hospital Spinal Rehabilitation Unit. Inclusion criteria for the study were spinal cord injured persons aged $15-29$ years who had completed their rehabilitation programmes at the Spinal Rehabilitation Unit.

\section{Instrumentation}

Face to face interviews were conducted using a semi-structured interview schedule to obtain in-depth information of the needs of SCI individuals in the community. The interview was a guided purposeful conversation which began with a 'grand tour' question:'Tell me what it's like for you to live with a spinal cord injury; how does spinal cord injury affect your life?" 


\section{Data Analysis}

To increase the trustworthiness of the study findings, the criteria of credibility, transferability, dependability and confirmability (Lincoln and Guba, 1985) were met through several strategies.

Credibility was obtained by presenting the transcribed data and emergent categories to 5 of the participants (member checking). Participants confirmed the accuracy of the transcripts and the interpretation of their comments.

Interviews were transcribed and compared to audio tape recordings to verify accuracy. Each transcript was carefully read through and scrutinised by the researcher and her supervisor. Transcripts were subjected to content analysis to identify core consistencies and meanings. Data were coded into broad categories as dictated by the research questions, for example, "how did having sustained a spinal cord injury impact on your life" During the initial category coding, the researcher identified and coded major themes in each interview. Emerging themes were written in the margins of each interview transcription. All the themes were listed and then grouped into categories. The themes discussed are those that were central to most of the participants.

\section{RESULTS AND DISCUSSION}

The demographics of the sample are reflected in Table 1. The mean age of the sample group was 16.5 (15-21) years. The following categories were identified from the data around the impact of SCI on the participants:

1. Social identity

2. Intrapersonal factors

3. Social support

4. Employment opportunities

\section{Social identity}

The theme of social identity describes the participants' personal struggle with adjustment in society. All the participants irrespective of age, injury or resulting disability; expressed their concerns about their personal struggle with their identity as well as society's struggle to integrate them. One of the participants expressed his struggle of self-identity and the uncertainty experienced on discharge from the hospital, by saying:
...'Is this the way to lead my life now?' 'How will my friends treat me... now that I am sitting in the wheelchair?' Another participant related, “...In the past I used to do a lot of things, but now in a split second my life changed..." (tetraplegia).

Adjusting to this new identity of not being able to do the same things as prior to the injury was described as a difficult process. The participants described how the injury served to shatter their self-perception and they highlighted an increase in negative feelings such as frustration, anger and stress. The participants recognised that there was an impact created by their own attitudes related to their self-identity often stemming from the difficult process of adjusting to a "new identity" after the injury. The issue of self identity has been reported in other studies (Carpenter 1994, Levins et al 2004). It is thus essential that health professionals realise that the change in body image after a spinal cord injury may cause significant psychological trauma. Individuals will thus need intervention to help them re-integrate the loss of their former body image and its effects on their new state.

\section{Intrapersonal and interpersonal factors}

Internal factors such as lack of motivation and lack of confidence were issues

Table 1: Demographic profile of youth with Spinal Cord Injuries.

\begin{tabular}{|lll|}
\hline & $\mathbf{n}$ & $\%$ \\
\hline Age & 4 & 40 \\
$15-17$ & 4 & 40 \\
$18-20$ & 2 & 20 \\
21 & & \\
\hline Gender & 8 & 80 \\
Male & 2 & 20 \\
Female & & \\
\hline Level of Education & 3 & 30 \\
Grade 8 & 1 & 10 \\
10 & 6 & 60 \\
Matric & & 50 \\
\hline Cause of Injury & 5 & 20 \\
Gunshot & 2 & 30 \\
Diving & 3 & 40 \\
Trauma & & 60 \\
\hline Type of Injury & 4 & \\
Quadriplegic & 6 & \\
Paraplegic & & \\
\hline
\end{tabular}

that the participants highlighted. In addition, the general insensitivity and negative perceptions that society had towards individuals with disability negatively impacted on their ability to deal with their disability. One participant who described himself as having stopped exercises, although actively involved in sports prior to the injury, said, “...You see sometimes when you are all alone; you don't feel motivated to exercise a lot you know like to do sports..." (paraplegia).

Another participant noted how he had stopped wheeling himself in the malls because of the attitudes from the general public: "I don't like going to many places 'cause people stare at you all the time and I don't like that, it feels like a humiliation when people stare at you, you feel like a nobody, like you are from a different planet...you see I used to go wheeling myself in the malls with my friends on weekends...in fact that's the biggest stress that makes me not like going to the malls anymore... " (paraplegia). A second participant voiced similar concerns saying, "The people here don't look at you the way they used to, they look at you and feel shame for you like I am dead... like I am some kind of freak."

Some of the intrapersonal and interpersonal factors mentioned by participants in this study, have been identified 
as factors that negatively impact on people with disabilities' quality of life in other studies. For instance, lack of motivation was identified as a major barrier to physical fitness by a majority of participants (54\%) in a study sample of adults with spinal cord injuries (Zemper et al., 2003). A study by Levins et al. (2004) found society's attitudes to be one of the major barriers in physical activity participation in a sample of spinal cord injured individuals.

\section{Social support}

Social support provided to individuals with spinal cord injury in this study included support from family, friends and health care professionals. The various types of support identified included emotional support and informational support. Emotional support was emphasised by most participants as coming from family and friends: "The first few months I couldn't cope .... I was very frustrated and I felt weak - my brother and my parents help me .... now I have friends who are also in wheelchairs and they motivate me ......"

Informational support described the advice or knowledge gained by participants from health professionals. One participant said: "People in the hospital like the physios and nurses gave us information on pressure sores and effects of smoking etc..." Physiotherapists' regards patient education as an important aspect of management and this study highlights the need to emphasise the information provided to spinal cord injured patients.

In addition the experiential knowledge of other people having survived spinal cord injuries made them valued sources of informational support. "...I have a friend who is long in the wheelchair, he is now eleven years in the wheelchair and he gives me a lot of advice... what to do and what to avoid...also here in school the friends that I have, ...we tell each other if something works for us..."

Social support has been reported as an important resource by people with chronic disabling conditions and physical disabilities including those with spinal cord lesions in a number of studies. In a study by Hampton (2001), social support was found to be the most influential factor on quality of life of young Chinese adults with spinal cord injuries. Given the importance attached to social support by participants, there is a need for rehabilitation professionals to involve family and friends in the rehabilitation process form an early stage.

\section{Employment opportunities}

Participants expressed concern on areas of their lives that they felt were essential to them such as employment opportunities. A participant reflected: "I would like to know about job opportunities for people with disabilities, because even now I am studying but I don't know if when I finish I will get a job...." This statement is important for health professionals as the WHO International Classification of Functioning, Disability and Health (WHO 2002) highlights the need for participation at societal level.

\section{CONCLUSION}

The study reveals that spinal cord injury impacts on more than just the physical capabilities of an individual. The process of adjusting to a spinal cord injury clearly affects the psychological and social aspect of an individual Rehabilitation programmes and health professionals involved with spinal cord injured patients need to be aware of the impact a spinal cord injury has on the individual. This study thus brings a fresh understanding of the impact of spinal cord injuries and highlights that when health professionals evaluate treatment outcomes, they also need to consider the broader concept of health related quality of life for spinal cord injured patients.

\section{REFERENCES}

Carpenter C 1994 The experience of spinal cord injury: the individual's perspectiveimplications for rehabilitation practice. Physical Therapy 74: 614-629

Chase B, Cornille T, English R 2000 Cord injuries. The Journal of Rehabilitation 66: 14-22

Conroy L, McKenna K 1999 Vocational outcome following spinal cord injury. Spinal Cord 37: 624-633
Frieg A, Hendry J 2001 Disability profile of grant recipients in a semi-rural area in South Africa. South Africa Journal of Physiotherapy 57: $23-27$

Hampton N 2001 Disability status, perceived health, social support, self-efficacy, and quality of life among people with spinal cord injury in the People's Republic of China. International Journal of Rehabilitation Research 24: $69-71$

Levins S, Redenbach D, Dyck I 2004 Individual and societal influences on participation in physical activity following Spinal cord injury: a qualitative study. Physical Therapy 84: 496-510

Lincoln Y, Guba E 1985 Naturalistic inquiry Sage publications, Newbury park, California

Nesathurai S 2000 The rehabilitation of people with spinal cord injury: Epidemiology of traumatic spinal cord in the United States. Massachusetts, USA. Library of Congress.

World Health Organisation 2002 International classification of functioning, disability and health. Geneva: WHO.

Zemper E, Tate D, Roller S, Forchheimer M, Chiodo A, Nelson V 2003 Assessment of holistic wellness program for persons with spinal cord injury. American Journal of Physical Medicine \& Rehabilitation 82: 957-968

Acknowledgement: This study was financially supported by the VLIR scholarship provided by the University of the Western Cape and its Flemish partners. 